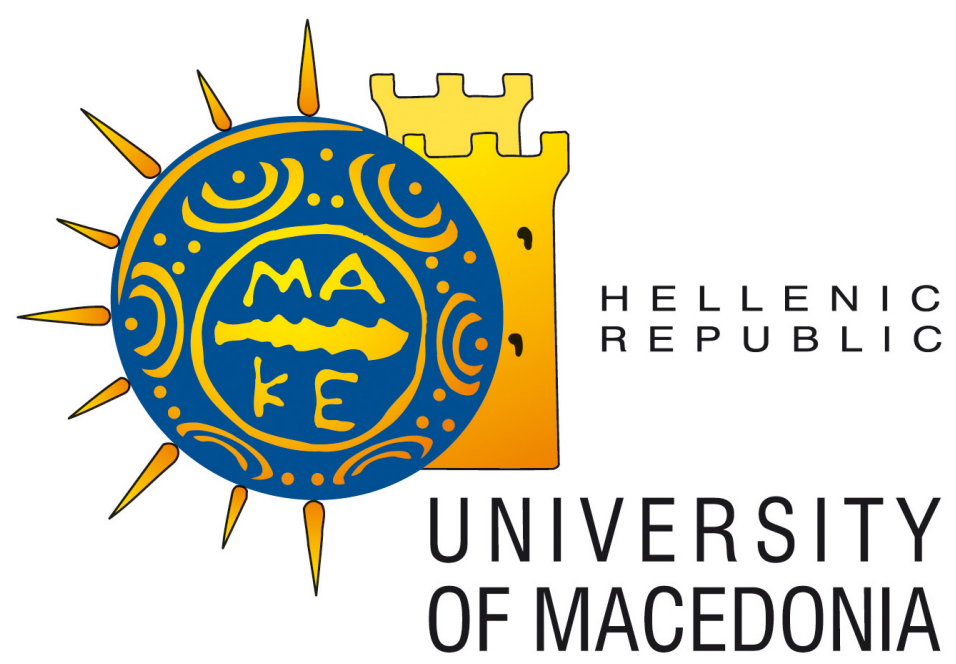

ISSN 1791-3144

\author{
University of Macedonia \\ Department of Economics
}

Discussion Paper Series

\title{
Uncertainty in the Public Debt Market and Stochastic Long-Run Growth
}

Panagiotis Tsintzos and Theologos Dergiades

\section{Discussion Paper No. 19/2010}

\footnotetext{
Department of Economics, University of Macedonia, 156 Egnatia str, 54006 Thessaloniki, Greece, Fax: + 30 (0) 2310891292

http://www.uom.gr/index.php?newlang=eng\&tmima=3\&categorymenu=2
} 


\title{
Uncertainty in the Public Debt Market and Stochastic Long-Run Growth
}

\author{
By \\ Panagiotis Tsintzos* and Theologos Dergiades*†
}

\begin{abstract}
In a continuous time model, a representative household has to allocate its investment and consumption in an optimal manner under conditions of uncertainty. In the present study it is hypothesized that there are two types of assets: a risk-free and a risky asset. The risk-free asset is assumed to be the physical capital, while at the same time uncertainty is allowed to result from the exogenous random variations in the public debt market, rendering in this way government bonds to act as the risky-asset. In the endogenous growth framework with productive public investment, the expected longrun growth rate, the dynamic path of consumption as well as the optimal allocation of investment between a risky and a riskless asset, are analytically derived. This kind of treatment allows us to create a locus for the long-run growth over the various levels of uncertainty. The outcome of the analysis is that a rise in uncertainty impacts negatively upon the long-run growth rate. In order to empirically assess the relationship between growth and uncertainty, we lay our emphasis on the US economy for the period 1957:1 to 2008:4. Within the framework of a bivariate BEKK-GARCH(1,1)-M model a significant negative relationship between uncertainty and economic growth has been established.
\end{abstract}

JEL Classification: C32, C51, H50, H63, O40.

Keywords: public debt management; stochastic optimal control; endogenous growth;

\footnotetext{
*Department of Economics, University of Macedonia, 156 Egnatia Street, Thessaloniki, Greece, E-mail addresses: tsintzos@uom.gr (P.Tsintzos); dergiades@uom.gr (T. Dergiades).

tCorresponding author.
} 


\section{Introduction}

The importance of public debt management lies in the fact that the government's debt portfolio is indisputably the largest financial portfolio in the country. As a result, the decisions made by the public debt manager (PDM) affect welfare and economic growth; therefore, her actions ought to be guided by a clear macroeconomic orientation rather than by an opportunistic desire for short-run gains. In OECD countries, the majority of the public debt management offices affirm, either formally or informally, that their main goal is to minimize the cost of servicing the debt. For example, in the Report of the Debt Management Review (1995) by the HM Treasury and the Bank of England it is noticeably stated that: "The objective of debt management policy is to minimize over the long term the cost of meeting the government's financial needs, taking account of the risk, whilst ensuring that debt management policy is consistent with monetary policy". The cost minimization objective, taking into account the risk of the corresponding debt structure, is critical primarily for the highly-indebted countries so they are able to sustain their debt. On the contrary, in developed countries with low public debt, such a cost minimization strategy could well be used to save funds, which in turn may serve productive and non-productive public spending, highlighting in this way the beneficial role of a successful debt managing strategy in growth and welfare.

Missale (1999, pp 131) argues that "a strategy aimed at reducing interest costs is justified only when risk premia result from: market imperfections; informational asymmetries; expectations failures; and the governments' inability to credibly commit to future policy actions". ${ }^{1}$ Relevant literature suggests that public debt issuing policies and strategies that may smooth or even eliminate the aforementioned matters are considered as optimal. A rise in the risk premia may result from various factors such as default risk, macroeconomic uncertainty, fiscal imbalance, lack of liquidity, volatility in the secondary market, political instability, matters related to monetary instability or even the transparency of the issuance pricing and auctioning of government securities. The IMF and the World Bank guidelines for the Public Debt Management (2003, pp 27) state that: "most countries have taken steps to increase the transparency of the auction process in the domestic market to reduce the amount of uncertainty in the primary market and achieve lower borrowing costs". Additionally, the same Public Debt Management (2003,

1 Issues such as: market imperfections, informational asymmetries, expectation failures and the government's inability to commit credibly to future policy actions, are extensively discussed in Missale (1999). 
pp 15) guidelines state that "it is important to note that all of the countries surveyed referred to the advantages of working collaboratively with market participants to develop their domestic government securities markets and minimize the amount of uncertainty in the market regarding government financing activities".

According to the above, one may argue that the reduction of uncertainty in the primary public debt market may reduce the risk premia and therefore minimize the cost of public debt. The insight received from the case studies reported within the Guidelines for Public Debt Management (2003), is that PDM takes legislative measures and implements strategies in order to achieve the coveted cost minimization. The chronological orientation of these strategies is mostly of a short to a medium term. Hence our intention is to examine the long-run effects of these short/medium oriented strategies in the economy. More specifically the focus lies in the appraisal of how changes in the level of uncertainty, stemming from the bond market, may shift the balanced growth path in a stochastic endogenous growth framework where endogenous growth rises from public investment. In order to act in such a manner, a micro-funded household behaviour is implemented, as in Merton (1971), where the choices about optimal consumption and investment are made under uncertainty, incorporating at the same time a hypothesis according to which the risky asset is the public debt and not the private capital. Finally, a solution is provided for the continuous time case.

The intuition is as follows: a rise in the uncertainty level requires an appropriate compensation to investors which is revealed by a subsequent increase in the risk premium of bonds. This in turn stimulates the debt dynamics via the increased cost of servicing the debt, and as a result the government which finances its productive public spending through its dynamic budget constraint, needs to reduce investment. At the same time, investors tend to adjust their optimal allocation of investment according to the changes of the aggregate risk and the expected return. These two reactions force down the ratio of productive public spending to private capital which is the key determinant of growth in the endogenous growth model under consideration. A more rigorous analysis of the mechanism at work will be pursued under the light of the proposed macro-model.

The remainder of this article is organized as follows: section 2 presents the proposed theoretical model. Section 3 proceeds with the analysis of the expected long-run growth under uncertainty. Section 4 illustrates the data and the econometric methodology. Section 5 provides a discussion on the empirical findings and finally, section 6 concludes. 


\section{The Model}

The representative household's optimal choices for the consumption and the allocation of investment between a risky and a risk-less asset (highlighted especially in Merton, 1971) caught the attention of the literature. The main source of uncertainty, modelled explicitly in most RBC and SDGE models, results in the exogenous stochastic variations of the dynamic innovation of technology. A technology shock alters the marginal product of labour, the marginal product of capital and output. This in turn alters interest rates, wages, taxes, capital formation or even the deficit and the public debt, depending on each model's idiosyncratic characteristics. The rational expectations mechanism allows agents to react optimally to these stochastic changes and to adjust their dynamic paths of consumption, labour or leisure and investment plans accordingly, thus leading the economy back to its steady state position. The usual investment choice in the aforementioned models is between a risky asset, that is private capital and a riskless asset, usually being the public debt. Since the present paper's main objective is to examine how the different levels of uncertainty in the bond market affect the long-run economic growth, the assumption made is that the economy's unique source of uncertainty stems from the bond market.

To provide a mathematical foundation, a typical decentralized competitive three sector model is developed. By letting the economy's single household to maximize its expected utility by choosing in an optimal manner its consumption and investment under the stochastic dynamic budget constraint, there is no substantial departure from Merton (1971). Formally, household's maximization problem can be shaped as follows:

$\max E \int_{0}^{\infty} e^{-\rho t} \frac{C^{\theta}}{\theta} d t$

s.t.

$d W=[r(1-h) W+R h W+\omega-C] d t+h W \sigma d z$

where, household wealth $(W)$ consists of private capital $(K)$ and government bonds $(B),(W=K+B), r$ is the interest rate and $\omega$ the wage rate. The share of wealth in government bonds is denoted as $h$ and consequently $1-h$ is the share of wealth in privately owned capital. The expected return of the risky asset $(B)$ is represented as $R$, with $R=r+f\left(\sigma^{2}\right)$ and $f^{\prime}\left(\sigma^{2}\right)>0, f^{\prime \prime}\left(\sigma^{2}\right)>0$. Actually the $f\left(\sigma^{2}\right)$ is the risk premium associated with the variance $\sigma^{2}$ of the Wiener process (white noise) $z$, 
affecting the bond market. Additionally, $\theta<1$ is the steepness of the CES utility function and $\rho>0$ is the household's anticipation for consumption.

The corresponding maximum principle of this problem results in the following Hamiltonian-Jacobi-Bellman equation:

$$
\rho V(W)=\max _{C, h}\left\{\frac{C^{\theta}}{\theta}+V^{\prime}(W)[r(1-h) W+R h W+\omega-C]+\frac{1}{2} h^{2} W^{2} \sigma^{2} V^{\prime \prime}(W)\right\}
$$

where, $V(W)$ is a value function. The optimality conditions are:

$$
\begin{gathered}
C=\left(V^{\prime}(W)\right)^{1 / 1-\theta} \\
h=\frac{(r-R) V^{\prime}(W)}{\sigma^{2} W V^{\prime \prime}(W)}
\end{gathered}
$$

The endogenous growth framework arises from the aggregate production technology specification, which is $Y=A K^{1-a} G^{a}$ ( $A$ denotes technology). ${ }^{2}$ The profit maximization behaviour of a competitive firm with no capital depreciation, defines the real interest rate and the wage rate as $r=(1-a)(1-\tau) A K^{-a} G^{a}$ and $\omega=a(1-\tau) A K^{1-a} G^{a}$, respectively. It is also assumed that $\tau$ is the tax rate (as government taxes output). Finally, the dynamic budget constraint of the government is $d B=(R B+G-T) d t+R h W \sigma d z$, with $T=\tau Y=\tau A K^{1-a} G^{a}$.

The analytical solution of consumption, investment and the long-run growth rate is provided through the identification of the $V(W)$ function. By substituting into (3) the optimality conditions (4) and (5), the following is obtained:

$$
\rho V(W)=-\frac{2(\theta-1) \sigma^{2}\left(V^{\prime}(W)\right)^{\theta / \theta-1} V^{\prime \prime}(W)+\theta V^{\prime}(W)\left((r-R)^{2} V^{\prime}(W)-2(\omega+r W) \sigma^{2} V^{\prime \prime}(W)\right)}{2 \theta \sigma^{2} V^{\prime \prime}(W)}
$$

A thorough examination of (4), (5) and (6), reveals the solution for the nonlinear differential equation (6) that has the following general form: $V(W)=\Psi W^{\theta}$, where $\Psi$ is

\footnotetext{
${ }^{2}$ Unlike most RBC and SDGE models, technology is constant.
} 
a coefficient to be determined. To this point it should be mentioned that the wage can be expressed as:

$\omega=a(1-\tau) A K^{1-a} G^{a}=a(1-\tau) A g^{a} K=a(1-\tau) A g^{a} W(1-h)$

considering that $W=K+B$ and $h W=B,(1-h) W=K$.

By calculating $V^{\prime}(W)$ and $V^{\prime \prime}(W)$ and replacing them back to equation (6), the relationship (8) is obtained after the use of some algebra and the method of determined coefficients:

$\Psi \theta=2^{1-\theta}\left(\frac{\Omega}{(\theta-1)^{2} \sigma^{2}}\right)^{\theta-1}$

where, $\Omega$ is:

$\Omega=-\left(r^{2}+R^{2}\right) \theta+2 r \theta\left(R+(\theta-1) \sigma^{2}+a g^{a}(\tau-1)\right)-2(\theta-1) \sigma^{2}\left(\rho+a g^{a} \theta(\tau-1)\right)$

$-2 a \operatorname{Rg}^{a} \theta(\tau-1)$

Finally, the analytical solutions for the optimal allocation of investment and consumption are obtained. The functional forms of these solutions are presented by the two subsequent relationships:

$$
C=\frac{W}{2}\left(\Omega /(\theta-1)^{2} \sigma^{2}\right) \quad \text { (9), and } \quad h=(R-r) /(1-\theta) \sigma^{2}
$$

\section{The Expected Long-Run Growth}

The balanced growth path along with the expected long-run growth corresponds to:

$$
\gamma=\dot{W} / W=\dot{C} / C=\dot{K} / K=\dot{B} / B=\dot{G} / G=\dot{Y} / Y
$$

Utilizing (2), (7), (8), (9), (10) and since $r=(1-a)(1-\tau) A K^{-a} G^{a}, W=K+B, h W=B$, $(1-h) W=K$ and $R=r+f\left(\sigma^{2}\right)$, the long-run growth rate expression is identified as: 


$$
\begin{aligned}
& \gamma=E \frac{\dot{W}}{W}=E \frac{d W / d t}{W} \Rightarrow \\
& \gamma=\frac{2(\theta-1) \sigma^{2}\left(\rho+g^{a}(A+a(A-1)(\theta-1))(\tau-1)+2 a g^{a}(1+(A-1) \theta)(\tau-1) f\left(\sigma^{2}\right)-(\theta-2)\left(f\left(\sigma^{2}\right)\right)^{2}\right.}{2(\theta-1)^{2} \sigma^{2}}
\end{aligned}
$$

where, $g$ is the ratio of public to private capital. Equation (11) in conjunction with all the afore-mentioned equations, provide the following equilibrium condition:

$$
\begin{aligned}
& \frac{-2 \sigma^{2}(\theta-1)\left(\rho+g^{a}(A+a(A-1)(\theta-1))(\tau-1)\right)-2 a g^{a}(1+(A-1) \theta)(\tau-1) f\left(\sigma^{2}\right)+(\theta-2) f\left(\sigma^{2}\right)}{2 \sigma^{2}(\theta-1)^{2}} \\
& =\frac{\sigma^{2}(\theta-1)\left(g^{a} \tau-g\right)+f\left(\sigma^{2}\right)\left(g^{a}((a-1) A(\tau-1)+\tau)-g+f\left(\sigma^{2}\right)\right)}{f\left(\sigma^{2}\right)}
\end{aligned}
$$

The expression of the growth rate is comprised by two basic factors: the endogenous ratio of public to private capital, which is fixed along the balanced growth path, and the exogenous level of uncertainty, $\sigma^{2}$. Equation (13) provides an equilibrium rule along the balanced growth path that determines the level of (expected) $g$, for different levels of uncertainty, $\sigma^{2}$. Therefore, the impact of a change in the level of uncertainty on the growth rate is revealed directly through $\sigma^{2}$ in equation (12) and indirectly to the ratio of public to private capital in equation (13). Provided that equation (13) is an implicit function, we turn to numerics in order to ascertain the behaviour of the long-run growth rate in relation to uncertainty.

Therefore, in order to investigate the relationship between economic growth and uncertainty, based on equations (12) and (13), a necessary condition is to supply reasonable qualitative and numerical properties, firstly for the risk premium function, $f\left(\sigma^{2}\right)$, and secondly for the allocation of optimal investment $h$. At this point, it should be mentioned that the optimal allocation of investment for the representative household $(h)$ as well as the expected rate of return $(R)$, have both already been replaced in equations (12) and (13) by their equivalents.

It has been already assumed that $f^{\prime}\left(\sigma^{2}\right)>0, f^{\prime \prime}\left(\sigma^{2}\right)>0$. A positive first derivative with respect to $\sigma^{2}$, simply lets the risk premium to rise as uncertainty rises, while a positive second derivative with respect to $\sigma^{2}$, permits the risk premium to keep on growing at an increasing pace, as $\sigma^{2}$ grows. For the $f\left(\sigma^{2}\right)$ specification we choose an 
exponential functional form and in particular the $f\left(\sigma^{2}\right)=\kappa e^{\lambda \sigma^{2}}{ }^{3}$ The appropriate choice of $\kappa>0$ and $\lambda>0$, needs to be made according to the properties of the $h$ ratio, which is naturally bounded in the space of $(0,1)$. Additionally, $\kappa$ and $\lambda$ should return a comparable risk premium value to the real interest rate.

The optimal allocation of investment can be written as $h=f\left(\sigma^{2}\right) /(1-\theta) \sigma^{2}$, or even as $h=\kappa e^{\lambda \sigma^{2}} /(1-\theta) \sigma^{2}$. The derivative of $h$ with respect to $\sigma^{2}$, can be either positive or negative. If $\sigma^{2}$ increases, $f\left(\sigma^{2}\right)$ increases as well, while the change of $h$ (increasing or decreasing) is driven by $\kappa>0$ and $\lambda>0$. Taking into account all the above-mentioned, the values of $\kappa=0.001$ and $\lambda=10$ are selected, so that the risk premium function is now specified as $f\left(\sigma^{2}\right)=0.001 e^{10 \sigma^{2}}$. This choice of values permits $f^{\prime}\left(\sigma^{2}\right)>0, f^{\prime \prime}\left(\sigma^{2}\right)>0$, and at the same time for a reasonable subspace of $\sigma^{2} \in(0.1,0.3)$, simulate the risk premium as illustrated below in Figure 1. The risk premium, in response to the changes in the level of uncertainty, varies within the range of $0.5 \%$ to $2 \%$. This range is considered to be reasonable since it may correspond for instance to the current spread of the 10-year bond between Germany and Spain. The above parameter values, with an appropriate value for $\theta=0.3$, simulate the optimal allocation of investment between the risky and riskless asset as presented in Figure 2 below. Figure 2 shows for the optimal allocation of investment that the compensation for the undertaken risk, increases by more than the risk. This process results in an increase of the share of public debt in household portfolio, provided that investors are compensated sufficiently for the undertaken risk, while default is not an option in this model. Empirical reasoning for the behaviour of $h$ comes from the observation that the public debt as percentage of GDP is rising for most advanced economies (IMF, 2010). Considering firstly, that advanced economies fluctuate around their balanced growth path in the presence of fiscal uncertainty and secondly, that the public debt as percentage of GDP increases, then the hypothesis of increase of the share of public debt $h$, is judged to be within reason. It should be stressed that the government here has a passive role and simply covers the demand of public debt, meeting in this way its dynamic budget constraint, rather than implementing a specific fiscal policy.

\footnotetext{
3 The criterion for the selection of the $\sigma^{2}$ specification was the concordance of the received results with reality. Therefore, through the process of trial and error, and after adopting several non-linear specifications, we came to the conclusion that the adopted exponential specification is the most suitable.
} 


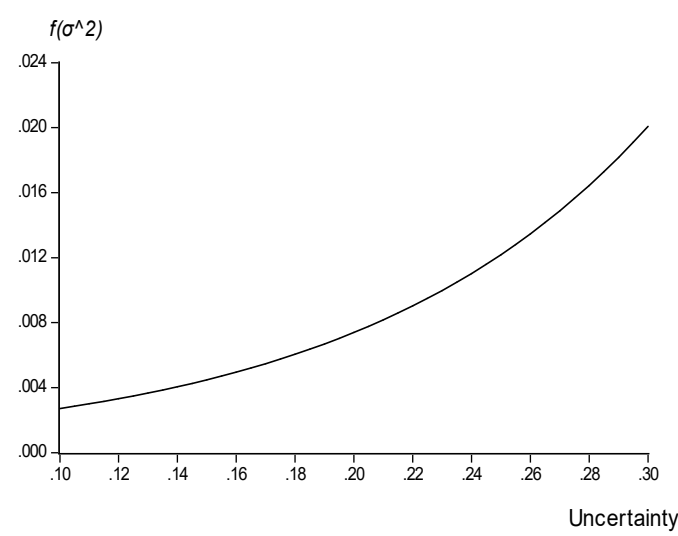

Figure 1

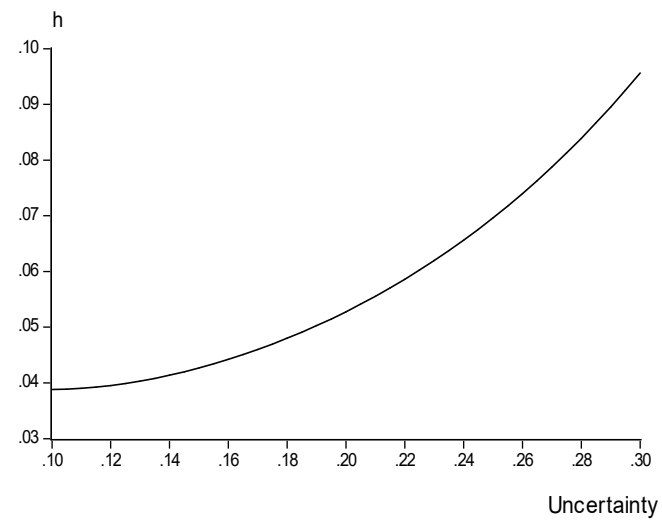

Figure 2

Optimal Allocation of Investment over Uncertainty

To proceed with the numerics, we utilize the commonly used values of $\tau=0.3$, $\rho=0.1, A=0.1$ and $a=0.25$, which for a given level of uncertainty $\left(\sigma^{2}=0.1\right)$, result to the values of $20 \%, 3.51 \%$ and $2.47 \%$ for the $g, r$ and $\gamma$, respectively. By letting $\sigma^{2} \in(0.1,0.3)$, we calculate a negative relation with the public to private capital ratio $g$, as seen in Figure 3 and together they reveal a negative relation with the expected longrun growth rate. Within the framework of the above equilibrium analysis, it is observed that a rise in uncertainty increases the risk premium associated to the government's debt, which in turn reallocates optimal household investment. Consequently, while the level of private capital increases and the funding of public capital (pubic investment) decreases, the overall effect on $g$, which is the main growth determinant, is negative (see Figure 3), leading therefore the excepted long-run growth rate to decrease.

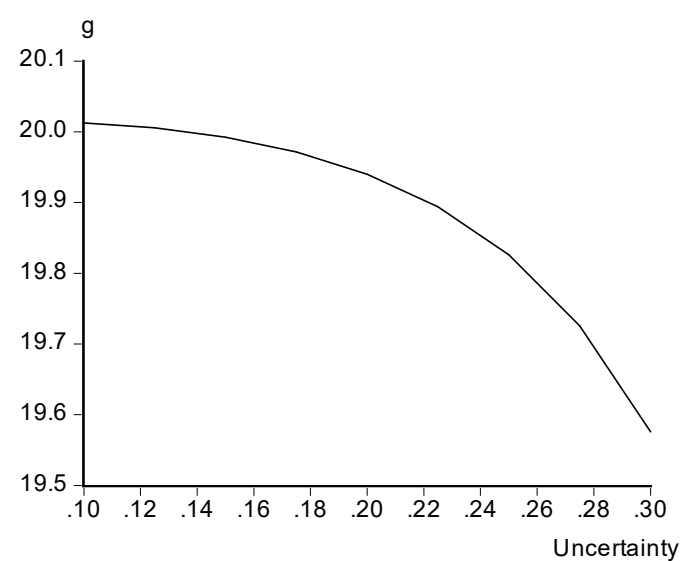

Figure 3

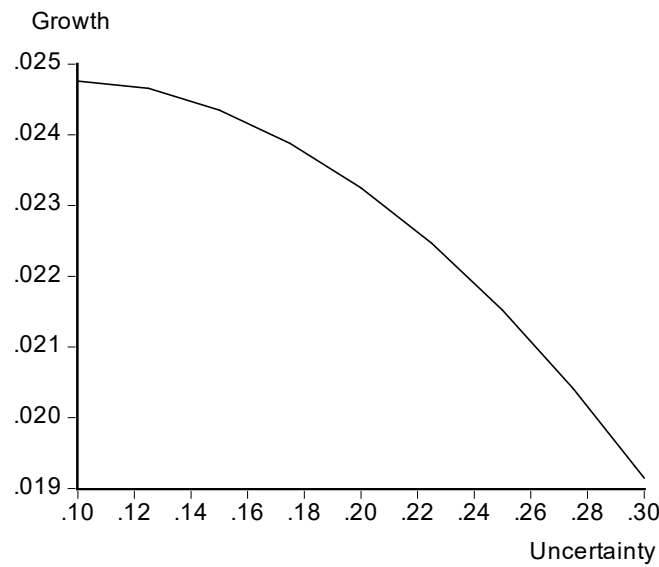

Figure 4 
In cases where the economy is in equilibrium, agents allocate optimally their wealth and consumption over time. Given that the economy is in equilibrium, we impose an exogenous increase in the level of uncertainty, $\sigma^{2}$. The optimal behaviour of the rational agents leads to appropriate adjustment of investment and consumption, according to the derived first order conditions. An increase in the level of uncertainty has an immediate positive effect on the level of the risk premium. This in turn affects the household's first order conditions that correspond to its optimal investment decision $(h)$. Should the derivative of equation $h=f\left(\sigma^{2}\right) /(1-\theta) \sigma^{2}$ with respect to $\sigma^{2}$ be positive, the optimal investment behaviour results to an increase in the public debt share of wealth $(h W)$ and at the same time to a decrease in the physical capital share of wealth $((1-h) W)$.

In the second section, it has been assumed that total wealth is $W=K+B$, while $h W=B$ and $(1-h) W=K$. In the short-run, the exogenous increase of uncertainty changes the equilibrium and moves the balanced growth path. The economy at this point is out of equilibrium and needs to go through a process of adjustment to progress on the transitional dynamic path that will bring the economy back to the balanced growth path. In the short-run, the optimality conditions derived from welfare maximization of the household and the composition of total wealth will lead to an increase in the stock of public debt and to a decrease in the stock of physical capital.

Concerning production, two short-run effects are realized: firstly, on the stock of physical capital and secondly, on the ratio of public to physical capital. It has been already indicated that the physical capital has been decreased in the short-run, due to the exogenously induced change in the level of uncertainty, leading therefore to a lower balanced growth path. This output decline, reduces the government's revenue from taxation, given the validity of $T=\tau Y=\tau A K^{1-a} G^{a}$, or $T=\tau A K g^{a}$. At the same time, the rise of the risk premium along with the rise of the equilibrium share of debt affect positively the debt dynamics, which in turn increase the cost of servicing the debt. These two effects reduce the amount of funds to be invested in productive public capital.

Finally, the ratio of the productive public capital to the physical capital, $g$, receives a lower steady state value, along the new balanced growth path, where $\dot{W} / W=\dot{C} / C=\dot{K} / K=\dot{B} / B=\dot{G} / G=\dot{Y} / Y$ grow at the same rate. Thus, the overall effect on the ratio of public to private capital is negative, reducing as a result the expected longrun growth rate. This result is not surprising as it is known that for the endogenous 
growth models with productive public spending and public debt, higher debt results in lower output growth (see Greiner, 2008). ${ }^{4}$

Taking into account the hypotheses made to build up this model, what has been made formal is the mechanism that allows uncertainty in the bond market to affect the long-run economic growth. Of course, the hypothesis according to which the risk stems solely from the bond market and not by production is considered as a quite strong assumption. Future work may relax this strong assumption by allowing the existence of two different types of uncertainty and permitting at the same time both assets to bear risk.

\section{Data and Econometric Methodology}

As it is shown in figure 4, the level of uncertainty stemming from the bond market (within a stochastic endogenous growth framework) impacts negatively upon the balanced growth path. To empirically investigate the relationship between economic growth and uncertainty we focus our attention to the US economy. Our study employs quarterly time series data spanning the period 1957:1 to 2008:4. The sample of our analysis is dictated solely by the availability of the data. The variables involved are: the 10-year government bond yield (percent per annum), the consumer price index (all items, city average), the gross domestic product and finally, the gross domestic product deflator $(2005=100)$. All data comes from the International Financial Statistics (IFS) database ${ }^{5}$ of the International Monetary Fund (IMF). Economic growth (percent per annum) is estimated by the logarithmic difference of the real gross domestic product series, while the real government bond yield is approximated by subtracting the annualized inflation series from the nominal 10-year government bond yield.

To assess uncertainty's impact upon economic growth, we exploit a bivariate GARCH-M model. Specifically, among the various GARCH-M type models we use the standard BEKK model for the specification of the conditional variance and covariance equations as initially suggested by Engle and Kroner (1995). ${ }^{6}$ The introduced bivariate BEKK GARCH (1,1)-M model is comprised of the economy's output growth rate and

\footnotetext{
${ }^{4}$ Provided that we assume firstly, a government that fulfils its dynamic budget constraint and secondly, that uncertainty comes only from the public bond market, the path of interrelations is quite different.

${ }^{5}$ http://www.imfstatistics.org/imf/

${ }^{6}$ To this point, it has to be mentioned that through the adopted econometric methodology our intention is to identify a possible significant negative relationship between risk and economic growth. If indeed the relationship proves to be negative, then this finding is not an indisputable piece of evidence for the validity of the presented economic mechanism. The established negative relationship may be due to other economic mechanisms.
} 
the real 10-year government bond yield. Given previous period available information set $\Omega_{t-1}$, the specification we propose for the two conditional mean equations, is the following:

$$
\begin{aligned}
& \Delta y_{t}=c_{y}+\sum_{i=1}^{j} a_{y, i} \Delta y_{t-j}+\sum_{i=1}^{j} \beta_{y, i} r_{t-j}+\varphi_{y} \log \left(h_{y, t}\right)+\xi_{y} \log \left(h_{r, t}\right)+\varepsilon_{y, t} \\
& r_{t}=c_{r}+\sum_{i=1}^{j} a_{r, i} r_{t-j}+\sum_{i=1}^{j} \beta_{r, i} \Delta y_{t-j}+\varphi_{r} \log \left(h_{r, t}\right)+\xi_{r} \log \left(h_{y, t}\right)+\varepsilon_{r, t}
\end{aligned}
$$

where, $\Delta y_{t}$ is the growth rate of real output, $r_{t}$ is the real long-term government bond yield, $\varepsilon_{y, t}$ and $\varepsilon_{r, t}$ are shocks to output and to bond market, respectively, $h_{j, t}$ is the $\operatorname{Var}_{t-1}\left(\varepsilon_{j, t}\right)$, with $j=y, r$ and finally, $c_{y}, c_{r}, a_{y, i}, a_{r, i}, \beta_{y, i}, \beta_{r, i}, \varphi_{y}, \varphi_{r}, \xi_{y}$ and $\xi_{r}$ are parameters to be estimated. Alternatively, equations (14) and (15) can be seen as a VAR model with two exogenous variables, that is $\log \left(h_{y, t}\right)$ and $\log \left(h_{r, t}\right)$, with the errors to be conditionally distributed as $\varepsilon_{t} \mid \Omega_{t-1} \sim N\left(0, H_{t}\right)$.

The rationale for the inclusion of the $\log \left(h_{y, t}\right)$ and $\log \left(h_{r, t}\right)$ terms into the conditional mean equations derives from our intention to assess the importance and the direction of the relationship between real output growth and bond market uncertainty. Of major interest in our study is the parameter associated to the $h_{r, t}$ term, that is $\xi_{y}$, since a negative and significant value would be a confirmation for the negative relationship between uncertainty and economic growth.

Within the framework of a bivariate BEKK GARCH(1,1)-M model, given the available information set $\Omega_{t-1}$, the conditional variance and covariance equations are modeled as functions of past errors as follows:

$$
\begin{aligned}
h_{y, t}= & c_{11}^{2}+c_{12}^{2}+b_{11}^{2} h_{y, t-1}+2 b_{11} b_{21} h_{y r, t-1}+b_{21}^{2} h_{r, t-1}+a_{11}^{2} \varepsilon_{y, t-1}^{2}+2 a_{11} a_{21} \varepsilon_{y, t-1} \varepsilon_{r, t-1}+ \\
& +a_{21}^{2} \varepsilon_{r, t-1}^{2} \\
h_{r, t}= & c_{22}^{2}+c_{12}^{2}+b_{22}^{2} h_{r, t-1}+2 b_{12} b_{22} h_{y r, t-1}+b_{12}^{2} h_{y, t-1}+a_{22}^{2} \varepsilon_{r, t-1}^{2}+2 a_{12} a_{22} \varepsilon_{y, t-1} \varepsilon_{r, t-1}+ \\
& +a_{12}^{2} \varepsilon_{y, t-1}^{2} \\
h_{y r, t}= & c_{11} c_{12}+c_{12} c_{22}+b_{11} b_{12} h_{y, t-1}+\left(b_{11} b_{22}+b_{12} b_{21}\right) h_{y r, t-1}+b_{21} b_{22} h_{r, t-1}+ \\
& +a_{11} a_{12} \varepsilon_{y, t-1}+\left(a_{11} a_{22}+a_{12} a_{21}\right) \varepsilon_{y, t-1} \varepsilon_{r, t-1}+a_{21} a_{22} \varepsilon_{r, t-1}
\end{aligned}
$$


Alternatively, equations (16)-(18) can be written in a more compact form using matrix notation as follows:

$H_{t}=C^{T} C+B^{T} H_{t-1} B+A^{T} \varepsilon_{t-1} \varepsilon_{t-1}^{T} A$

where, $H_{t}$ is the positive definite $2 \times 2$ conditional variance-covariance matrix of the errors, $C$ is $2 \times 2$ upper triangular matrix of coefficients and finally, $B$ and $A$ are also $2 \times 2$ unrestricted matrices of coefficients. Actually, the diagonal elements of the $B(A)$ matrix depict the volatility (error) persistence in the conditional variances of output growth and real bond yield, while the off-diagonal elements of the $B(A)$ matrix depict how the one period lagged volatility (squared error) of the real bond yield influences the conditional variance of output growth and vice versa.

\section{Empirical Results}

Empirical analysis begins with the detection of unit roots since prior to the estimation of the bivariate BEKK-GARCH-M model, we need to ensure that both variables used to specify the conditional mean equations are stationary. For this purpose, the standard ADF test along with the KPSS test are implemented, with and without the inclusion of a time trend. Based on the results presented in Table 1, it is inferred that the real output and the nominal 10-year government bond yield are clearly non-stationary variables. However, when the ADF test was applied to the growth of output and to the real 10-year government bond yield, we rejected the null hypothesis of non-stationarity for both variables, while the KPSS test does not allow us to reject the null hypothesis of stationarity for both variables.

Table 1. ADF and KPSS tests for unit roots.

\begin{tabular}{|c|c|c|c|c|}
\hline \multirow{2}{*}{ Variable } & \multicolumn{2}{|c|}{$\mathrm{ADF}^{*}$ test statistic } & \multicolumn{2}{|c|}{ KPSS** LM statistic } \\
\hline & no trend & trend & no trend & trend \\
\hline $\mathrm{y}$ & -1.6399 & -2.1420 & 1.8220 & 0.2517 \\
\hline$\Delta y$ & -10.280 & -10.407 & 0.1904 & 0.0345 \\
\hline$r_{n}$ & -1.6414 & -1.5384 & 0.4069 & 0.3989 \\
\hline $\mathrm{r}$ & -3.2134 & -3.5897 & 0.2270 & 0.1579 \\
\hline \multicolumn{5}{|c|}{$\begin{array}{l}\text { Notes: }{ }^{*} \text { The Schwartz information criterion used for the lag selection on Augmented Dickey-Fuller test } \\
\text { (Dickey and Fuller, } 1979 \text { and 1981) and the maximum lag length was set to nine. ** The Bartlett Kernel } \\
\text { spectral estimation method was selected for Kwiatkowski et al. (1992) test. The } 1 \%, 5 \% \text { and } 10 \% \text { critical } \\
\text { values for the ADF test without trend (with trend) are: }-3.46(-4.00),-2.87(-3.43) \text { and }-2.57(-3.13) \text {, } \\
\text { respectively. The } 1 \%, 5 \% \text { and } 10 \% \text { critical values for the KPSS test without trend (with trend) are: } 0.73 \\
(0.21), 0.46(0.14) \text { and } 0.34(0.11) \text {, respectively. }\end{array}$} \\
\hline
\end{tabular}


Another issue related to the specification of the bivariate BEKK-GARCH model is the presence of a possible long-run relationship. In cases where equilibrium is confirmed, the inclusion of the disequilibrium term in the conditional mean equation is crucial since otherwise inferences based on the estimated system of equations will be of an ambiguous quality. Given that the level series for real output is an I(1) variable, while the real 10year government bond yield series is an $I(0)$ variable, we examine the existence of a possible long-run relationship by employing the Pesaran et al. (2001) ARDL or bounds testing approach to cointegration. Table 2 presents the bounds testing results, from which it is inferred that there is no evidence for the existence of a long-run equilibrium. In particular, the value of the ARDL F-statistics for alternative lag lengths, ranging from 2 to 5 , is always below the lower critical threshold, something which implies failure to reject the null hypothesis of no cointegration.

Table 2. ARDL test for cointegration.

\begin{tabular}{|c|c|c|c|c|}
\hline \multicolumn{5}{|c|}{ ARDL approach to cointegration } \\
\hline & \multicolumn{4}{|c|}{ Alternative lag lengths } \\
\hline & 2 & 3 & 4 & 5 \\
\hline$F_{y}(y \mid r)$ & 1.8544 & 2.6191 & 3.1697 & 4.0431 \\
\hline$F_{r}(r \mid y)$ & 1.7413 & 1.9727 & 3.2175 & 3.5411 \\
\hline
\end{tabular}

Finally, a correctly specified GARCH model demands for the involved variables, to be serially independent and at the same time the existence of autoregressive conditional heteroskedasticity (ARCH) effects should be verified. Therefore, the Ljung-Box Qstatistic and the Langrage Multiplier (LM) test statistic were implemented. The testing results are illustrated in Table 3. Based on the reported $p$-values, the Q-statistic confirms the absence of serial correlation in the residuals, while the LM test verifies the presence of ARCH effects.

Table 3. Test for serial correlation and ARCH effects.

\begin{tabular}{|c|c|c|c|c|}
\hline Variable & $\mathrm{Q}(4)$ & $\mathrm{Q}(6)$ & $\mathrm{Q}(8)$ & $\mathrm{LM}(4)$ \\
\hline \multirow[b]{2}{*}{$\Delta y$} & 1.726 & 2.282 & 7.119 & 3.751 \\
\hline & $(0.786)$ & $(0.892)$ & $(0.524)$ & $(0.005)$ \\
\hline \multirow[b]{2}{*}{$r$} & 0.390 & 4.563 & 8.800 & 7.881 \\
\hline & $(0.983)$ & $(0.601)$ & $(0.359)$ & $(0.000)$ \\
\hline
\end{tabular}

Notes: Q(4), Q(6) and Q(8) are the Ljung-Box statistics (Ljung and Box, 1979) for testing the fourth, sixth and eighth order of serial correlation, respectively, for the residuals recovered from an $\mathrm{AR}(12)$ specification for $\Delta y$ and from an $\operatorname{AR}(5)$ specification for $r$. The LM(4) refers to the Langrage Multiplier test statistic for testing the presence of ARCH effects in the series using four lags. 
Assuming conditional normality, we estimated the bivariate BEKK-GARCH-M $(1,1)$ model, by maximizing the following Log-likelihood function:

$$
L(\theta)=-\frac{T n}{2}+\ln 2 \pi-\frac{1}{2} \sum_{t=1}^{T}\left(\ln \left|H_{t}\right|+\varepsilon_{t}^{T} H_{t}^{-1} \varepsilon_{t}\right)
$$

The maximization algorithm used is the Berndt, Hall, Hall and Houseman. The results of the estimated model are presented in Table $4 .^{7}$ The first two upper parts of the table show the coefficient estimates along with their associated $p$-values for the system of equations 14 to 18, while the lower part illustrates the standardized residuals diagnostics.

Our foremost interest concentrates on the sign and the significance of the $\xi_{y}$ coefficient in the conditional mean equation for the growth rate of output. Judging from the results presented in Table 4, our finding confirms the existence of a negative and significant relationship between uncertainty and economic growth even at the $1 \%$ significance level. ${ }^{8}$ The remaining three conditional variances incorporated to the mean equations of output growth and real long-term bond yield remain insignificant at the $5 \%$ significance level. To preserve space we do not proceed with the interpretation of the persistence coefficients (diagonal elements) as well as of the information transmission coefficients (off-diagonal elements), since something like this is straightforward and out of interest for our study.

Finally, to assess whether the estimated model is correctly specified, we need to ensure that the standardized residuals are iid standard normal variables. For that reason we tested the mean and the variance of the standardized residuals setting as null hypotheses that $\mu=0$ and $\sigma^{2}=1$, respectively. Clearly, in both cases we fail to reject the null hypotheses, as seen in Table 4. Additionally, we employed the Ljung-Box Q-statistic in order to examine the presence of autocorrelation in the standardized residuals. From the results given in Table 4, we fail to reject the null hypothesis of no serial correlation. Consequently, the estimated specification seems to be well specified, providing therefore consistent estimates.

\footnotetext{
${ }^{7}$ The lag-length of the estimated model was based on the Schwartz information criterion.

${ }^{8}$ To this point it is important to mention that the coefficient under consideration consistently proved to remain negative and highly significant in all other alternative specifications employed before the adoption of the final one.
} 
Table 4. Estimates of the bivariate BEKK-GARCH(1,1)-M model

Conditional mean equations (14) and (15)

$$
\begin{gathered}
\Delta y_{t}=\underset{(0.320)}{0.214}+\underset{(0.000)}{1.020} \Delta y_{t-1}-\underset{(0.574)}{0.054} \Delta y_{t-2}-\underset{(0.000)}{0.262} \Delta y_{t-3}+\underset{(0.059)}{0.207} r_{t-1}-\underset{(0.542)}{0.103} r_{t-2}+\underset{(0.721)}{0.011 r_{t-3}}+\underset{(0.165)}{0.204} \log \left(h_{y, t}\right)-\underset{(0.001)}{0.405} \log \left(h_{r, t}\right) \\
r_{t}=\underset{(0.000)}{0.501+} \underset{(0.000)}{1.168} r_{t-1}-\underset{(0.064)}{0.261} r_{t-2}+\underset{(0.706)}{0.032} r y_{t-3}-\underset{(0.371)}{0.038} \Delta y_{t-1}+\underset{(0.677)}{0.024} \Delta y_{t-2}-\underset{(0.524)}{0.023} \Delta y_{t-3}+\underset{(0.103)}{0.143} \log \left(h_{y, t}\right)-\underset{(0.095)}{0.141 \log \left(h_{r, t}\right)}
\end{gathered}
$$

Conditional variance-covariance equations (16), (17) and (18).

$$
h_{y, t}=\underset{(0.000)}{0.199^{2}}+\underset{(0.985)}{0.002^{2}}+\underset{(0.000)}{0.777^{2}} h_{y, t-1}+\underset{(0.000)}{2(0.777)} \underset{(0.372)}{0.029)} h_{y r, t-1}+\underset{(0.372)}{0.029^{2}} h_{r, t-1}+\underset{(0.000)}{0.592^{2}} \varepsilon_{y, t-1}^{2}-\underset{(0.000)}{2(0.592)}\left(\underset{(0.019)}{0.115)} \varepsilon_{y, t-1} \varepsilon_{r, t-1}-\underset{(0.019)}{0.115^{2}} \varepsilon_{r, t-1}^{2}\right.
$$

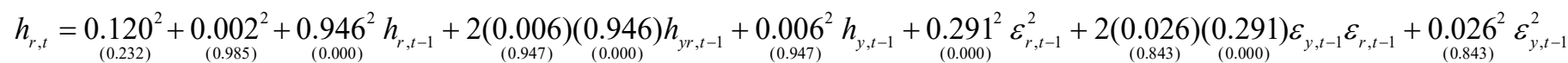

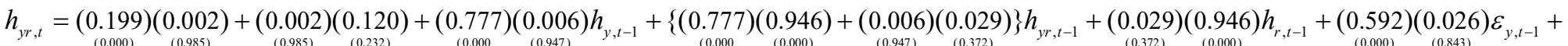

$$
\begin{aligned}
& +\{\underset{(0.000}{\{(0.592)} \underset{(0.000)}{(0.291)}-\underset{(0.843)}{(0.026)} \underset{(0.019)}{(0.115)}\} \varepsilon_{y, t-1} \varepsilon_{r, t-1}-\underset{(0.019)}{(0.115)(0.291)} \varepsilon_{r, t-1}
\end{aligned}
$$

Standardized residuals diagnostics

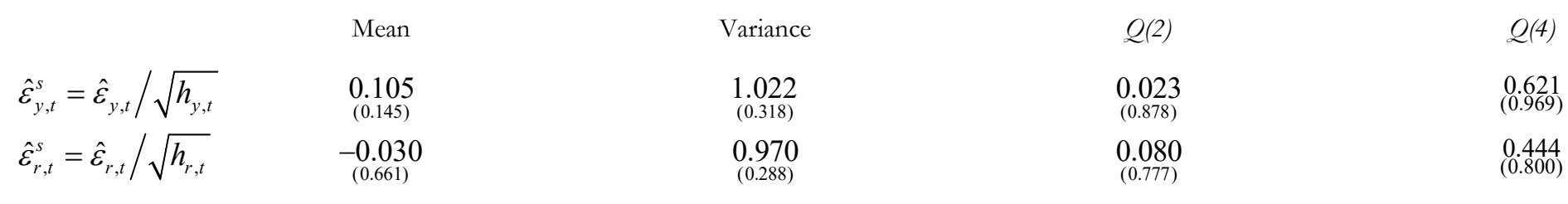

Notes: Parameter estimates for equations 14-18; $p$-values are presented within the parentheses; $\hat{\varepsilon}_{y, t}^{s}$ and $\hat{\varepsilon}_{r, t}^{s}$ represent the standardized residuals for the growth of output and the real government 10 -year bond yield, respectively; The null hypothesis for the mean column in the standardized residuals diagnostics panel is that: $\mu=0$, while the null hypothesis for the variance column is that: $\sigma^{2}=1$ 


\section{Concluding remarks}

In this article we tried to investigate uncertainty's potential impact on the long-run economic growth. Accordingly, we developed a continuous time stochastic endogenous growth model under the light of Merton (1971), allowing the household's choices with respect to the optimal allocation of consumption and investment to be made under the presence of uncertainty. Within the pre-mentioned endogenous growth framework with productive public investment, the expected long-run growth rate, the dynamic path of consumption as well as the optimal allocation of investment between a risky and a riskless asset, are analytically derived through the relevant Hamiltonian-Jacobi-Bellman equation. It has been found that an increase in uncertainty raises the risk premium of pubic bonds and diminishes the public to private capital ratio which in turn leads to a reduction of the long-run growth rate. At last, we tried to provide empirical support for the revealed negative relationship between uncertainty and economic growth, by means of a bivariate BEKK-GARCH (1,1)-M model. Our empirical finding, based on US data, revealed a negative and significant relationship between economic growth and bond market uncertainty. The negative relationship established in the empirical part of this article, cannot be attributed exclusively to the economic mechanism revealed by our theoretical model, provided that this negative relationship may be due to other economic mechanisms.

\section{References}

Dickey, D.A. and Fuller, W.A. (1979). Distribution of the Estimators for Autoregressive Time Series with a Unit Root. Joumal of the American Statistical Association 74, 427-431.

Dickey, D.A. and Fuller, W.A. (1981). Likelihood Ratio Statistics for Autoregressive Time series with a Unit Root. Econometrica 49, 1057-1072.

Engle, R.F. and Kroner, K.F. (1995). Multivariate simultaneous generalized ARCH. Econometric Theory 11, 122-150.

Guidelines for Public Debt Management (2003). IMF and World Bank.

Greiner, A. (2008). Does it pay to have a balanced government budget? Journal of Institutional and Theoretical Economics 164, 460-76.

International Monetary Fund, (2010). Navigating the Fiscal Challenges Ahead, IMF staff Report 14/5, Department of Fiscal Affairs, Washington. 
Kwiatkowski, D., Phillips, P.C.B., Schmidt, P. and Shin, Y. (1992). Testing the Null Hypothesis of Stationary against the Alternative of a Unit Root. Journal of Econometrics 54, 159-178.

Ljung, G. and G. Box (1979). On a Measure of Lack of Fit in Time Series Models. Biometrika 66, 265-270.

Merton, R. C. (1971). Optimum Consumption and Portfolio Rules in a Continuous-Time Model. Journal of Economic Theory 3, 373-413.

Missale, A. (1999). Public Debt Management. Oxford University Press.

Narayan, P.K. (2005). The saving and investment nexus for China: evidence for cointegration tests. Applied Economics 37, 1979-1990.

Pesaran, M.H., Shin, Y. and Smith, R.J. (2001). Bounds testing approaches to the analysis of level relationships. Journal of Applied Econometrics 16, 289-326.

Report of Debt Management Review, (1995). HM Treasury and Bank of England. 